\title{
Dinâmica populacional de plantas daninhas na cultura do milho em função de adubação e manejo ${ }^{1}$
}

\author{
Population dynamics of weeds in maize culture in relation to fertilization and \\ management
}

\author{
Maria Lita Padinha Corrêa ${ }^{2 *}$, João Carlos Cardoso Galvão ${ }^{2}$, Anastácia Fontanetti ${ }^{3}$, Lino Roberto Ferreira ${ }^{4}$ e \\ Glauco Vieira Miranda ${ }^{5}$
}

\begin{abstract}
Resumo - O objetivo do trabalho foi avaliar o estabelecimento populacional das comunidades das plantas daninhas, durante seis anos agrícolas consecutivos de milho cultivado no sistema plantio direto orgânico e tradicional, intermediado por um sistema de plantio convencional. Os experimentos foram conduzidos nos anos agrícolas 2003/04 até 2008/09. O delineamento experimental adotado foi o de blocos casualizados com quatro repetições. Os tratamentos avaliados foram: SDT1 (semeadura direta sem adubação e com aplicação de herbicidas no manejo das plantas daninhas); SDT2 (semeadura direta com adubação mineral na dose de $300 \mathrm{~kg} \mathrm{ha}^{-1}$ do formulado 8-28-16 + $100 \mathrm{~kg} \mathrm{ha}^{-1}$ de nitrogênio em cobertura, e com aplicação de herbicidas); SDT3 (semeadura direta, adubação com composto orgânico, na dose de $40 \mathrm{~m}^{3} \mathrm{ha}^{-1}$, e com aplicação de herbicidas); e SDO (semeadura direta utilizando composto orgânico, na dose de $40 \mathrm{~m}^{3} \mathrm{ha}^{-1}$, e roçada no manejo das plantas daninhas). Concluiu-se que a dinâmica populacional de plantas daninhas na cultura do milho foi influenciada pelo manejo do solo (aração e gradagem) e que o tipo de adubação não proporcionou alteração na dinâmica populacional.
\end{abstract}

Palavras-chave - Milho. Erva daninha. Plantio direto. Agricultura orgânica.

\begin{abstract}
The aim of this work was to evaluate the weed establishing (and unwanted plant) populations during six consecutive agricultural years for maize crops. The systems studied were till, both organic and traditional, intermediated by a traditional plantation system. The experiments were carry out in the agricultural years 2003/04 until 2008/09, in the experimental area in southeast of the Minas Gerais State), which is owned by the Federal University of Viçosa. The treatments were SDT1 (till without fertilizer and herbicide application ); SDT2 (till with mineral fertilizer (300 kg ha-1 with of 8-28-16 (N-P-K) plus $100 \mathrm{~kg} \mathrm{ha}^{-1}$ of nitrogen for side fertilization, and the herbicide application): SDT3 (till with fertilizer with organic compost in a dose of $40 \mathrm{~m}^{3} \mathrm{ha}^{-1}$ and herbicide application ); SDO (organic till with organic compost in a dose of $40 \mathrm{~m}^{3} \mathrm{ha}^{-1}$, and mowing). We can conclude that the herbicide application or the clearing of the ground stimulated a greater alteration in the establishing of weed (unwanted plant) communities than the type of fertilizer used.
\end{abstract}

Key words - Maize. Weed. Tillage. Organic agriculture.

\footnotetext{
*Autor para correspondência

${ }^{1}$ Recebido para publicação em 15/042010; aprovado em 13/01/2011

Parte da Tese de doutorado do segundo autor, apresentada ao programa de pós-graduação em Fitotecnia/DFT/UFV

${ }^{2}$ Bolsista CNPq, Departamento de Fitotecnia/DFT/UFV, Avenida Peter Henry Rolfs, s/n, Campus Universitário, Viçosa-MG, Brasil, 36.570-000, litapc10@hotmail.com,jgalvao@ufv.br

${ }^{3}$ Centro de Ciências Agrárias/UFSCAR, Rod. Anhanguera, Km 174, Caixa Postal 330, Araras-SP, Brasil, 13.600-970, anastacia@cca. ufscar.br ${ }^{4}$ Bolsista CNPq, Departamento de Fitotecnia/DFT/UFV, Avenida Peter Henry Rolfs, s/n, Campus Universitário, Viçosa-MG, Brasil, 36.570-000, lroberto@ufv.br, glaucovmiranda@ufv.br
} 


\section{Introdução}

A agricultura orgânica, normalmente, realiza intensivos preparos do solo no sistema convencional. A intensidade do preparo leva a questionamentos sobre a sustentabilidade do sistema e a qualidade do solo, em razão de proporcionar perdas tanto do solo como de nutrientes, além da sua compactação, adensamento e diminuição da matéria orgânica. O cultivo orgânico em sistema plantio direto é uma alternativa viável de manejo do solo, pois possibilita a manutenção dos restos culturais, proporcionando, além de outros benefícios, o aumento da matéria orgânica.

O sistema de plantio direto consolidou-se como tecnologia conservacionista largamente aceita entre os agricultores, havendo sistemas adaptados a diferentes regiões e diferentes níveis tecnológicos (CRUZ et al., 2006).

Entretanto, existem dificuldades na implantação do sistema plantio direto orgânico referente ao controle das plantas daninhas e da cultura de cobertura, pois não há dessecantes recomendados para a agricultura orgânica e os herbicidas de pós-emergência também são proibidos. Assim, no controle das plantas daninhas, é essencial que haja cultivos na entressafra de culturas formadoras de palhada.

De acordo com Fontanetti et al. (2006), o manejo das plantas daninhas no cultivo orgânico em sistema de plantio direto é, sem dúvida, o principal entrave técnico na atualidade e um dos principais motivos da recusa do sistema plantio direto pelos produtores orgânicos.

$\mathrm{Na}$ cultura do milho, as plantas daninhas podem se tornar um grande problema e sua interferência no rendimento de grãos varia de acordo com o grau de competição entre elas, o que dependerá do tipo de comunidade infestante, das características da cultura, das condições edafoclimáticas e do período de convivência. Esses fatores devem ser manejados para que a interferência das plantas daninhas na cultura seja minimizada, tornando possível o cultivo do milho no plantio direto orgânico (CHIOVATO et al., 2007; KOSLOWSKI et al., 2002). Estima-se que, em áreas com controle das plantas daninhas, as perdas na produtividade de grãos de milho sejam na ordem de 13\% (CARVALHO et al., 2007).

O conhecimento da dinâmica e da interferência das plantas daninhas é pressuposto fundamental para a tomada de decisão quanto ao tipo e à época de manejo. A dinâmica populacional refere-se a mudanças na composição da comunidade infestante no tempo, considerando o número e a dominância relativa de cada espécie no agroecossistema (CARDINA et al., 1995; JAKELAITES et al., 2003a).

A adoção de práticas de manejo que visam a posicionar a cultura em situação competitiva vantajosa em relação às plantas daninhas constitui-se em alternativa viável para reduzir ou até eliminar a utilização de herbicidas.
Ainda são incipientes os estudos sobre o comportamento da comunidade de plantas daninhas em áreas com plantio direto de milho orgânico, ao longo do tempo, sendo estes estudos importantes para a melhoria da produtividade do milho. Nesse sistema, pode ser necessária uma aração esporádica do solo, a cada três ou quatro anos da adoção do sistema de plantio direto, já que, sem a utilização de herbicidas, algumas espécies são beneficiadas pelo sistema de controle adotado (CHIOVATO et al., 2007; FONTANETTI et al., 2006; VAZ de MELO, 2004). Estas espécies podem ser controladas com o enterrio pela aração e gradagem.

Desse modo, o presente trabalho tem por objetivo avaliar o estabelecimento populacional das comunidades de plantas daninhas de milho cultivado com semeadura direta e diferentes fontes de adubação e manejos das plantas daninhas durante seis anos agrícolas consecutivos.

\section{Material e métodos}

Os experimentos foram conduzidos nos anos agrícolas 2003/04 até 2008/09, na Estação experimental de CoimbraMG, pertencente à Universidade Federal de Viçosa.

A área experimental de 1984 até 2002 foi cultivada em parcelas permanentes com adubação mineral e outra com adubação orgânica, sendo o preparo do solo feito com uma aração e duas gradagens (GALVÃO, 1995). No ano agrícola de 2003/04, essas parcelas passaram a ser cultivadas no sistema de semeadura direta com a manutenção dos tratamentos originais (fontes minerais solúveis e orgânicas de adubação), numa sequência de milho e aveia preta (Avena strigosa Schreb).

$\mathrm{Na}$ safra de 2006/2007, uma semana antes do plantio do milho, toda a área Experimental foi arada e gradeada, método usado para controlar as plantas daninhas. Nos anos subsequentes, 2007/08 e 2008/09, voltaram-se ao sistema de semeadura direta.

O delineamento experimental adotado foi o de blocos casualizados com quatro repetições. Cada parcela experimental teve área total de $64 \mathrm{~m}^{2}$, com $12 \mathrm{~m}^{2}$ centrais de área útil. Nos anos agrícolas 2003/2004 a 2007/08, a variedade de milho utilizada foi UFVM 100 - Nativo e no ano agrícola 2008/09, a variedade utilizada foi UFVM 200 - Soberano, ambas de polinização aberta. Em todos os anos manteve-se a população de 50.000 plantas ha- ${ }^{-1}$.

Os tratamentos avaliados foram: SDT1 (semeadura direta sem adubação e com aplicação de herbicidas no manejo das plantas daninhas); SDT2 (semeadura direta com adubação mineral na dose de $300 \mathrm{~kg} \mathrm{ha}^{-1}$ do formulado 8-28-16 + $100 \mathrm{~kg} \mathrm{ha}^{-1}$ de nitrogênio em cobertura, e com aplicação de herbicidas); SDT3 (semeadura direta, 
adubação com composto orgânico, na dose de $40 \mathrm{~m}^{3} \mathrm{ha}^{-1}$, e com aplicação de herbicidas); e SDO (semeadura direta utilizando composto orgânico, na dose de $40 \mathrm{~m}^{3} \mathrm{ha}^{-1}$, e roçada no manejo das plantas daninhas).

O solo é classificado de Argissolo VermelhoAmarelo e as características químicas do solo, nos sistemas de manejo estudados, estão discriminadas na Tabela 1 .

A aveia preta foi semeada a lanço $\left(80 \mathrm{~kg} \mathrm{ha}^{-1} \mathrm{de}\right.$ sementes). No florescimento, as plantas de aveia preta foram cortadas com ceifadeira, ficando a palhada exposta ao sol para dessecação natural no sistema plantio direto orgânico SDO. Nos sistemas plantio direto tradicional SDT1, SDT2 e SDT3, a dessecação foi feita com glyphosate na dose de $720 \mathrm{~g}$ i.a. por hectare. Utilizou-se pulverizador costal, com regulador de pressão e com volume de calda aplicada de $100 \mathrm{~L} \mathrm{ha}^{-1}$.

No SDT2, o adubo formulado foi aplicado no sulco de plantio (300 $\mathrm{kg} \mathrm{ha}^{-1}$ da fórmula 8-28-16), simultaneamente ao semeio do milho, e o nitrogênio $\left(100 \mathrm{~kg} \mathrm{ha}^{-1} \mathrm{~N}\right)$ foi aplicado em cobertura quando o milho estava no estádio de quatro folhas completamente expandidas.

No SDO e no SDT3, a adubação foi realizada com composto orgânico na dose de $40 \mathrm{~m}^{3} \mathrm{ha}^{-1}$, aplicado em superfície ao lado da linha de semeio, após a emergência do milho.

O controle de plantas daninhas no plantio direto tradicional (SDT1, SDT2 e SDT3) foi realizado com a aplicação dos herbicidas atrazine $\left(1,5 \mathrm{~kg} \mathrm{ha}^{-1}\right) \mathrm{e}$ nicossulfuron (12 $\mathrm{g} \mathrm{ha}^{-1}$ ) em pós-emergência, nos estádios de quatro e oito folhas completamente desenvolvidas do milho. No plantio direto orgânico (SDO), o manejo das plantas daninhas foi feito por meio de duas roçadas com ceifadeira motorizada manual, nos estádios de quatro e oito folhas completamente desenvolvidas do milho.

Em cada ano agrícola, o estudo da dinâmica das plantas daninhas foi realizado efetuando-se três amostragens por parcela, com quadrado com $0,25 \mathrm{~m}$ de lado, lançado ao acaso na área útil de cada parcela. Essas amostras foram coletadas nos estádio de quatro folhas completas do milho, antes da aplicação dos herbicidas em pós-emergência e antes do primeiro corte das plantas daninhas com a ceifadeira no sistema orgânico, aproximadamente 25 dias após o plantio.

Em cada amostragem, as plantas foram cortadas rente ao solo, devidamente identificadas e separadas por espécies e famílias e em seguida secas em estufa de ventilação forçada de ar, por 72 horas, a $70{ }^{\circ} \mathrm{C}$, para determinação de massa das plantas secas. Uma vez obtidos o número de indivíduos por espécie e a matéria seca, foi realizada a análise descritiva através de parâmetros fitossociológicos representados pela importância relativa (IR\%), conforme descrição a seguir (PITELLI, 2000).

Índice do valor de importância (IVI), determinado por:

$\mathrm{IVI}=\mathrm{DeR}+\mathrm{FeR}+\mathrm{DoR}$

Em que:

A densidade relativa (DeR) é obtida ao dividirse o número de indivíduos de uma determinada espécie encontrada nas amostragens pelo número total de indivíduos amostrados, a frequência relativa $(\mathrm{FeR})$ é determinada pela frequência absoluta de uma espécie, dividida pela soma da frequência absoluta de todas as espécies, a dominância relativa (DoR) refere-se à divisão da biomassa acumulada por uma determinada espécie pela biomassa seca total acumulada por toda a comunidade de plantas daninhas.

A importância relativa (IR\%) é determinada pela divisão do índice de valor de importância de determinada população pelo somatório dos índices de valor de importância de todas as populações da comunidade infestante.

A escolha do índice de importância relativa para descrever as mudanças populacionais da comunidade infestante e das espécies daninhas deve-se ao fato de o mesmo ser o que melhor expressa a relação entre as populações de plantas daninhas componentes da comunidade infestante, pois considera a frequência de ocorrência, o número de indivíduos e a massa seca acumulada dessas populações (CARVALHO et al., 2008).

Os dados referentes à temperatura média $\left({ }^{\circ} \mathrm{C}\right)$ e precipitação pluvial $(\mathrm{mm})$ durante a condução dos experimentos estão apresentados na Tabela 2.

Tabela 1 - Resultado dos valores médios de características químicas de amostras do solo da área experimental em 2009

\begin{tabular}{|c|c|c|c|c|c|c|c|c|}
\hline \multirow{2}{*}{ Tratamentos* } & \multirow{2}{*}{$\mathrm{PH} \mathrm{H}_{2} \mathrm{O}$} & $\mathrm{Ca}^{2+}$ & $\mathrm{Mg}^{2+}$ & $\mathrm{K}$ & SB & CTC (T) & \multirow{2}{*}{$\frac{\mathrm{P}}{\mathrm{mg} \mathrm{dm^{-3 }}}$} & \multirow{2}{*}{$\frac{\mathrm{MO}}{\mathrm{dag} \mathrm{kg}^{-1}}$} \\
\hline & & \multicolumn{5}{|c|}{ 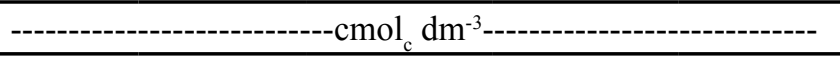 } & & \\
\hline SDT1 & 5,2 & 2,3 & 1,4 & 0,44 & 4,14 & 7,94 & 2,6 & 3,7 \\
\hline SDT2 & 4,8 & 1,4 & 0,7 & 0,48 & 2,58 & 7,70 & 13,3 & 2,6 \\
\hline SDT3 & 5,7 & 3,8 & 1,7 & 0,72 & 6,22 & 9,85 & 43,9 & 4,4 \\
\hline SDO & 5,7 & 3,8 & 2,0 & 0,65 & 6,44 & 9,91 & 35,7 & 4,5 \\
\hline
\end{tabular}

*SDT1 (semeadura direta sem adubação e com herbicida); SDT2 (semeadura direta com adubação mineral e herbicida); SDT3 (semeadura direta com composto orgânico e herbicida) e SDO (semeadura direta com composto orgânico e roçada) 
Tabela 2 - Precipitação acumulada (mm) por decênio (dez em dez dias): entre os dias 1-10, 11-20 e 21-30 e temperatura média $\left({ }^{\circ} \mathrm{C}\right)$ observada no período de condução dos experimentos, novembro de 2003 até abril de 2009. Coimbra-MG

\begin{tabular}{|c|c|c|c|c|c|c|c|c|c|c|c|c|}
\hline \multirow{4}{*}{ Mês } & \multicolumn{12}{|c|}{ Ano Agrícola } \\
\hline & \multicolumn{4}{|c|}{2003} & \multicolumn{4}{|c|}{2004} & \multicolumn{4}{|c|}{2005} \\
\hline & \multicolumn{3}{|c|}{ Precipitação por decênio (mm) } & \multirow{2}{*}{$\mathrm{T}\left({ }^{\circ} \mathrm{C}\right)$} & \multicolumn{3}{|c|}{ Precipitação por decênio (mm) } & \multirow{2}{*}{$\mathrm{T}\left({ }^{\circ} \mathrm{C}\right)$} & \multicolumn{3}{|c|}{ Precipitação por decênio (mm) } & \multirow{2}{*}{$-\mathrm{T}\left({ }^{\circ} \mathrm{C}\right)$} \\
\hline & $1-10$ & $11-20$ & $21-30$ & & $1-10$ & $11-20$ & $21-30$ & & $1-10$ & $11-20$ & $21-30$ & \\
\hline Jan & - & - & - & - & 74 & 146 & 164 & 19,5 & 17 & 78 & 63 & 22,7 \\
\hline Fev & - & - & - & - & 72 & 146 & 221 & 21,9 & 7 & 116 & 78 & 22,1 \\
\hline Mar & - & - & - & - & 79 & 29 & 79 & 21,5 & 153 & 48 & 93 & 22,3 \\
\hline Abr & - & - & - & - & 93 & 12 & 33 & 28,8 & 8 & 3 & 64 & 21,1 \\
\hline Mai & - & - & - & - & 9 & 14 & 13 & 18,2 & 1 & 2 & 46 & 18,8 \\
\hline Jun & - & - & - & - & 40 & 2 & 3 & 15,7 & 1 & 21 & 22 & 17,0 \\
\hline Jul & - & - & - & - & 4 & 40 & 1 & 15,5 & 11 & 25 & 1 & 16,1 \\
\hline Ago & - & - & - & - & 0 & 0 & 0 & 17,0 & 13 & 19 & 0 & 18,2 \\
\hline Set & - & - & - & - & 1 & 0 & 0 & 20,1 & 0 & 8 & 29 & 19,9 \\
\hline Out & - & - & - & - & 23 & 24 & 16 & 20,6 & 6 & 0 & 57 & 22,0 \\
\hline Nov & 86 & 20 & 88 & 21,5 & 81 & 56 & 59 & 21,8 & 54 & 45 & 43 & 20,6 \\
\hline Dez & 48 & 116 & 146 & 22,8 & 145 & 94 & 147 & 21,9 & 63 & 151 & 29 & 20,5 \\
\hline \multirow{4}{*}{ Mês } & \multicolumn{12}{|c|}{ Ano Agrícola } \\
\hline & \multicolumn{6}{|c|}{2006} & \multicolumn{6}{|c|}{2007} \\
\hline & \multicolumn{4}{|c|}{ Precipitação por decênio $(\mathrm{mm})$} & & $\mathrm{T}(\mathrm{\circ} \mathrm{C})$ & \multicolumn{4}{|c|}{ Precipitação por decênio (mm) } & \multirow{2}{*}{\multicolumn{2}{|c|}{$\mathrm{T}\left({ }^{\circ} \mathrm{C}\right)$}} \\
\hline & $1-10$ & & $11-20$ & $21-30$ & & & $1-10$ & & $11-20$ & $21-30$ & & \\
\hline Jan & 8 & & 10 & 90 & & 23,1 & 91 & & 70 & 198 & & 22,6 \\
\hline Fev & 13 & & 66 & 21 & & 23,7 & 52 & & 40 & 0 & & 22,3 \\
\hline Mar & 91 & & 47 & 7 & & 22,8 & 0 & & 23 & 0 & & 22,3 \\
\hline Abr & 27 & & 58 & 0 & & 20,5 & 0 & & 3 & 30 & & 22,2 \\
\hline Mai & 1 & & 1 & 3 & & 17,0 & 0 & & 0 & 22 & & 20,0 \\
\hline Jun & 0 & & 0 & 14 & & 15,8 & 4 & & 0 & 0 & & 17,0 \\
\hline Jul & 1 & & 0 & 0 & & 15,2 & 0 & & 0 & 6 & & 16,5 \\
\hline Ago & 0 & & 0 & 0 & & 18,2 & 0 & & 0 & 0 & & 18,6 \\
\hline Set & 0 & & 24 & 39 & & 18,8 & 16 & & 0 & 0 & & 18,0 \\
\hline Out & 11 & & 26 & 3 & & 20,6 & 0 & & 40 & 48 & & 20,8 \\
\hline Nov & 28 & & 29 & 0 & & 21,2 & 28 & & 3 & 17 & & 21,8 \\
\hline Dez & 16 & & 45 & 140 & & 22,5 & 46 & & 104 & 58 & & 22,8 \\
\hline
\end{tabular}




\begin{tabular}{|c|c|c|c|c|c|c|c|c|}
\hline \multirow{4}{*}{ Mês } & \multicolumn{8}{|c|}{ Ano Agrícola } \\
\hline & \multicolumn{4}{|c|}{2008} & \multicolumn{4}{|c|}{2009} \\
\hline & \multicolumn{3}{|c|}{ Precipitação por decênio (mm) } & \multirow{2}{*}{$\mathrm{T}\left({ }^{\circ} \mathrm{C}\right)$} & \multicolumn{3}{|c|}{ Precipitação por decênio (mm) } & \multirow{2}{*}{$\mathrm{T}\left({ }^{\circ} \mathrm{C}\right)$} \\
\hline & $1-10$ & $11-20$ & $21-30$ & & $1-10$ & $11-20$ & $21-30$ & \\
\hline Jan & 45 & 44 & 163 & 21,5 & 78 & 35 & 89 & 22,4 \\
\hline Fev & 71 & 8 & 73 & 22,7 & 15 & 117 & 13 & 23,1 \\
\hline Mar & 67 & 113 & 23 & 22,7 & 30 & 49 & 188 & 20,7 \\
\hline Abr & 57 & 22 & 8 & 22,5 & 4 & 12 & 0 & 18,4 \\
\hline Mai & 0 & 0 & 0 & 18,1 & - & - & - & - \\
\hline Jun & 1 & 0 & 11 & 15,7 & - & - & - & - \\
\hline Jul & 33 & 0 & 0 & 15,3 & - & - & - & - \\
\hline Ago & 2 & 0 & 0 & 18,1 & - & - & - & - \\
\hline Set & 0 & 96 & 32 & 18,5 & - & - & - & - \\
\hline Out & 4 & 25 & 1 & 20,4 & - & - & - & - \\
\hline Nov & 61 & 105 & 54 & 21,2 & - & - & - & - \\
\hline Dez & 63 & 261 & 144 & 22,1 & - & - & - & - \\
\hline
\end{tabular}

\section{Resultados e discussão}

Nos seis anos agrícolas avaliados, foram identificadas 20 espécies de plantas daninhas, distribuídas emnove famílias. No presente trabalho, foramrepresentadas as seis espécies daninhas mais constantes: Artemisia verlotorum, Cynodon dactylon, Cyperus rotundus, Bidens pilosa, Ipomoea grandifolia e Commelina benghalensis.

Os resultados da dinâmica da comunidade de plantas daninhas que infestaram a cultura do milho nos diferentes sistemas de plantio direto estão representados pela Importância Relativa (IR\%) das espécies nas Figuras 1 a 6.

No primeiro ano de implantação do sistema plantio direto (2003/04), a espécie Artemisia verlotorum (losna) obteve importância relativa (IR\%) inferior a $20 \%$, tanto nos sistemas de plantio direto tradicionais (SDT1 e SDT2) como no sistema de plantio direto orgânico (SDO). No ano agrícola 2004/05, não houve infestação da espécie no tratamento SDT2. Observou-se, no ano 2005/06, que a semeadura direta proporcionou aumento na IR\% da $A$. verlotorum em todos os tratamentos avaliados e os maiores valores, ao longo das avaliações, foram observados no SDT1 (semadubação)(FIG. 1). Essa espécieprovavelmente se adapta a solos de menor fertilidade (SDT1) ou a uma maior IR\%, que, nesse sistema, foi em decorrência da falta de concorrência com o milho e com outras espécies.

Ao longo das avaliações, verificou-se que o manejo com glifosate aplicado nos tratamentos SDT1, SDT2 e SDT3 não foi eficaz no controle da $A$. verlotorum.
Jakelaites et al. (2004) observaram, no consórcio entre a Brachiaria decumbens e o milho, que as espécie de plantas daninhas perenes de propagação vegetativa (Artemisia verlotorum e Cyperus rotundus) não foram controladas pela mistura de herbicida (nicosulfurom + atrazine), independentemente da dose aplicada. De acordo com Dias et al. (2007), a tolerância de certas espécies de plantas daninhas a herbicidas é resultado da capacidade inata da espécie em suportar aplicações de herbicidas nas doses recomendadas, sem alterações marcantes em seu crescimento e/ou desenvolvimento.

No sistema plantio direto orgânico, cujo manejo das plantas daninhas foi efetuado com duas roçadas (SDO), a losna apresentou taxas de IR\% menores ou próximas aos valores encontrados pelos outros tratamentos (FIG. 1). Os resultados da roçada foram equivalentes ao uso do herbicida no controle da $A$. verlotorum ao longo das avaliações.

A partir do ano agrícola 2008/09 em que há novamente o equilíbrio do sistema de plantio direto, os valores da IR\% da espécie voltam a patamares próximos aos do ano agrícola 2005/06, ano anterior à aração (FIG. 1).

Segundo Lorenzi (2000), a importância da $A$. verlotorum como planta daninha vem aumentando nos estados do sul e sudeste do Brasil, graças à sua eficiente capacidade reprodutiva, pois além de a espécie produzir sementes, possui um caule subterrâneo (rizoma) que garante sua perpetuação. Após o corte da parte aérea, ocorre uma rápida rebrota dos rizomas que repovoam a região, tornando o controle mais difícil (BRIGHENTI et al., 1993). 


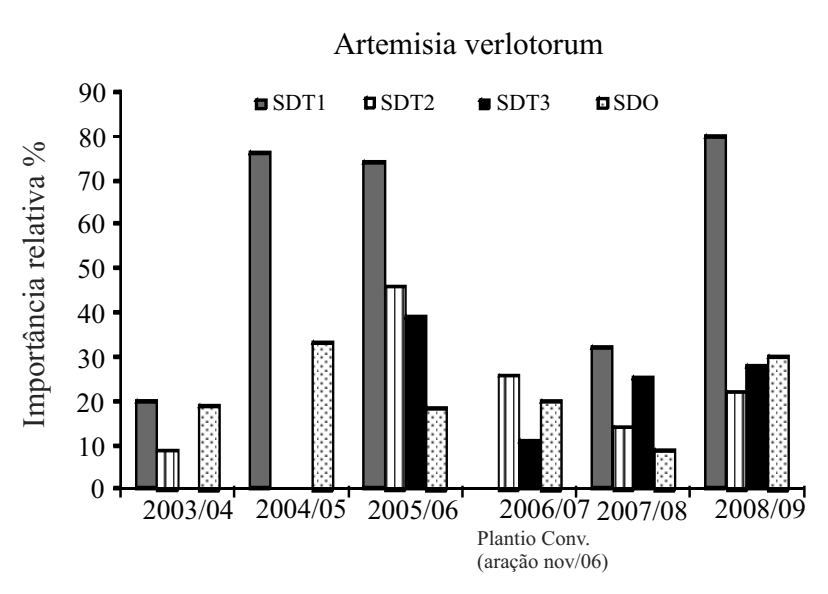

Época de avaliação

Figura 1 - Importância relativa de Artemisia verlotorum nos diferentes sistemas SDT1 (sem adubação, com herbicida); SDT2 (com adubação mineral e herbicida); SDT3 (adubado com composto orgânico e com herbicida); e SDO (adubado com composto orgânico e roçada), durante seis anos agrícolas

A espécie é tolerante à maioria dos herbicidas utilizados, principalmente na cultura do milho e soja, e o uso contínuo do mesmo produto nessas áreas causa alterações na flora nativa no sentido de uma seleção a favor da espécie. Nesse sentido, a aração realizada após 3 anos de plantio direto pode ser uma alternativa para controlar essa espécie, uma vez que os rizomas serão cortados e enterrados, dificultando a rebrota e diminuindo a infestação nos anos seguintes.

As taxas de importância relativa (IR\%) da espécie Cynodon dactylon (grama-seda) foram menores do que da $A$. verlotorum (FIG. 2). Verificou-se que no primeiro ano de plantio direto a espécie apresentou IR\% maior no sistema de plantio direto orgânico, SDO, enquanto no sistema plantio direto com adubação mineral (SDT2) não houve infestação da espécie.

$\mathrm{O}$ efeito da aração e gradagem realizado em 2006/07, diferentemente do apresentado pela $A$. verlotorum, estimulou a $C$. dactylon em todos os sistemas de plantio direto. Essa espécie se reproduz vegetativamente por meio de rizomas e estolões contidos no solo. Assim, a aração e a gradagem proporcionaram maior dispersão dessas estruturas no solo, estimulando sua germinação (LORENZI, 2000). Observa-se na Figura 2 que após a retomada do sistema de plantio direto nos anos 2007/2008 e 2008/2009 a importância dessa espécie diminui, provavelmente em função do não revolvimento do solo.

Os resultados observados indicam que o plantio direto facilita o controle dessa espécie.

No primeiro ano de plantio direto, a espécie Bidens pilosa obteve IR\% alta tanto no plantio direto tradicional

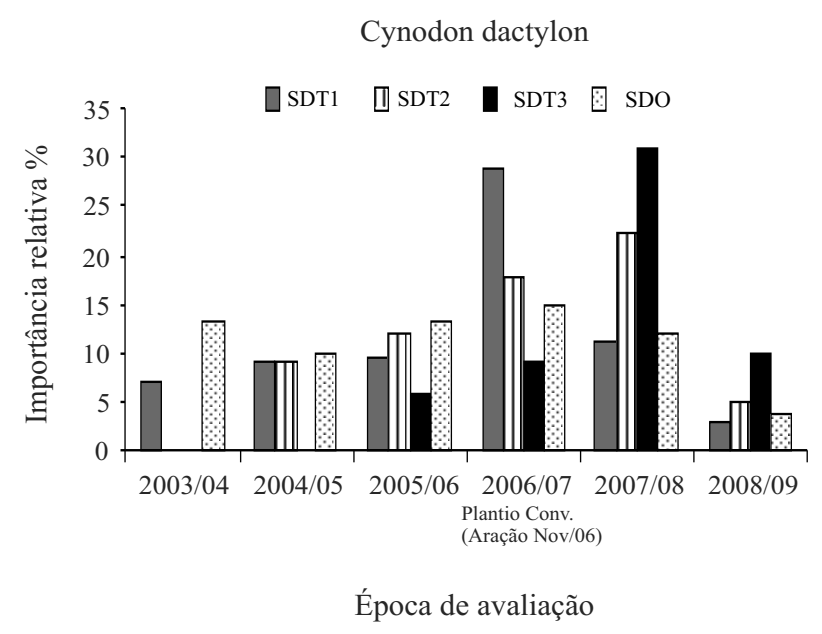

Figura 2 - Importância relativa de Cynodon dactylon nos sistemas SDT1 (sem adubação, com herbicida); SDT2 (com adubação mineral e herbicida); SDT3 (adubado com composto orgânico e herbicida); e SDO (adubado com composto orgânico e roçada), durante seis anos agrícolas

(SDT1 e SDT2), quanto no plantio direto orgânico (SDO). Com a continuidade do plantio direto, ocorreu controle total da espécie em todos os tratamentos tradicionais (SDT1, SDT2 e SDT3) em razão do uso do glyphosate para dessecação e do uso da mistura dos herbicidas atrazine e nicossulfuron em pós-emergente (FIG. 3).

Após a aração e gradagem realizada na safra de 2006/07, houve aumento da IR\% da espécie $B$. pilosa no tratamento SDT3, e na safra de 2007/08, um ano após a retomada do sistema plantio direto, a espécie voltou a infestar os outros tratamentos tradicionais (SDT1 e SDT2). A espécie $B$. pilosa se propaga via sementes e a maior exposição de suas sementes na superfície do solo em decorrência da aração, provavelmente, proporcionou maior percentual de germinação, já que a espécie é classificada como fotoblástica positiva. Trabalho realizado por Souza et al. (2009), estudando a germinação de $B$. pilosa em diferentes profundidades de semeadura, verificou maior percentual germinativo nas menores profundidades e redução no percentual germinativo a partir de $3 \mathrm{~cm}$ de profundidade. Esse fato é evidente quando se observa aumento da IR\% no sistema de plantio direto orgânico no ano agrícola 2007/2008. Observou-se também que com a retomada do sistema de plantio direto ocorreu redução da IR\% nos tratamentos tradicionais com a utilização de herbicidas até total controle da espécie em 2008/2009 (FIG. 3).

Porém, no SDO, apesar de ocorrer redução da IR da B. pilosa com a retomada do sistema de plantio direto, ao longo das avaliações, a importância relativa foi superior a $20 \%$, indicando que a roçada não proporciona 
controle eficaz da espécie, confirmando os resultados de Chiovato et al. (2007).

O comportamento da espécie $B$. pilosa é cíclico, ou seja, no início do plantio direto a espécie foi encontrada em todos os tratamentos (tradicionais e/ou orgânico), com o passar dos anos, a espécie é observada apenas no sistema orgânico, justamente por esse não utilizar os herbicidas. O mesmo comportamento foi observado após a aração e gradagem.

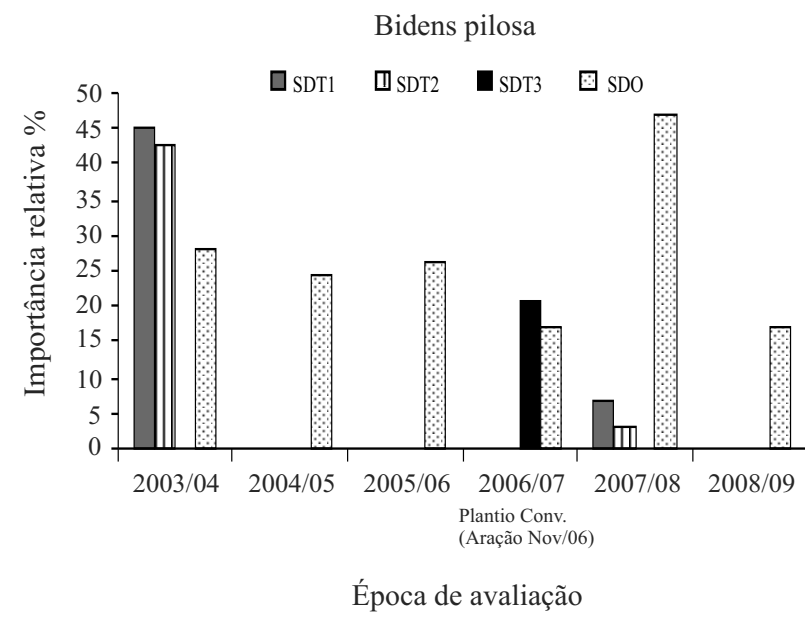

Figura 3 - Importância relativa da espécie Bidens pilosa nos sistemas SDT1 (sem adubação, com herbicida); SDT2 (com adubação mineral e herbicida); SDT3 (adubado com composto orgânico, com herbicida); e SDO (adubado com composto orgânico e roçada), durante seis anos agrícolas

A espécie Cyperus rotundus está entre as que apresentaram as maiores porcentagens de IR\%. No primeiro ano da semeadura direta (2003/04), a espécie apresentou baixa importância relativa independentemente do tipo de sistema adotado (FIG. 4).

Segundo Silva et al. (2002), quando em condições ambientais favoráveis (temperatura elevada e intensidade luminosa), o estabelecimento da espécie C. rotundus é rápido devido ao intenso crescimento vegetativo e à produção de tubérculos, sendo estes o motivo da sua vantagem competitiva com as culturas. Sua grande capacidade de sobrevivência no agroecossistema se deve a um eficiente sistema reprodutivo, constituído de rizomas, bulbos basais, tubérculos e sementes.

No sistema de plantio direto sem adubação (SDT1), a espécie $C$. rotundus apresentou baixa importância relativa em todos os anos avaliados. Esse fato se deve, provavelmente, à competição estabelecida com a espécie $A$. verlotorum, predominante nesse sistema.
Vale ressaltar que a aração e gradagem proporcionaram aumento da $\mathrm{IR} \%$ da $C$. rotundus nos tratamentos SDT1 e SDT2, diminuindo a IR\% no tratamento tradicional SDT3 e no plantio direto orgânico (SDO).

De acordo Ferreira et al. (2000), o revolvimento do solo pode separar os tubérculos dos rizomas, reduzindo a dormência e favorecendo a brotação da espécie assim como o seu estabelecimento.

No primeiro ano após aração (2007/08) e retorno do sistema de plantio direto, verificou-se diminuição da IR\% da C. rotundus em todos os sistemas estudados. Contudo, na avaliação seguinte (2008/2009), a IR\% da espécie aumentou em todos os tratamentos, com maior porcentagem no tradicional SDT2. Nesse mesmo ano, houve diminuição na produção de matéria seca da espécie de cobertura, aveia preta, em todos os tratamentos. A diminuição da palhada provavelmente contribuiu para maior desenvolvimento da C. rotundus. Jakelaitis et al. (2003b) verificaram que a ausência de palhada favoreceu a brotação dos tubérculos de C. rotundus. Segundo Miles et al. (1996), a temperatura do solo é um dos principais fatores ambientais que afetam a brotação dos tubérculos de tiririca quando a umidade do solo é adequada. Travlos et al. (2009) verificaram brotação de $95 \%$ de tubérculos de $C$. rotundus localizados a $5 \mathrm{~cm}$ do solo, quando foram submetidos a altas variações de temperatura diurna do solo.

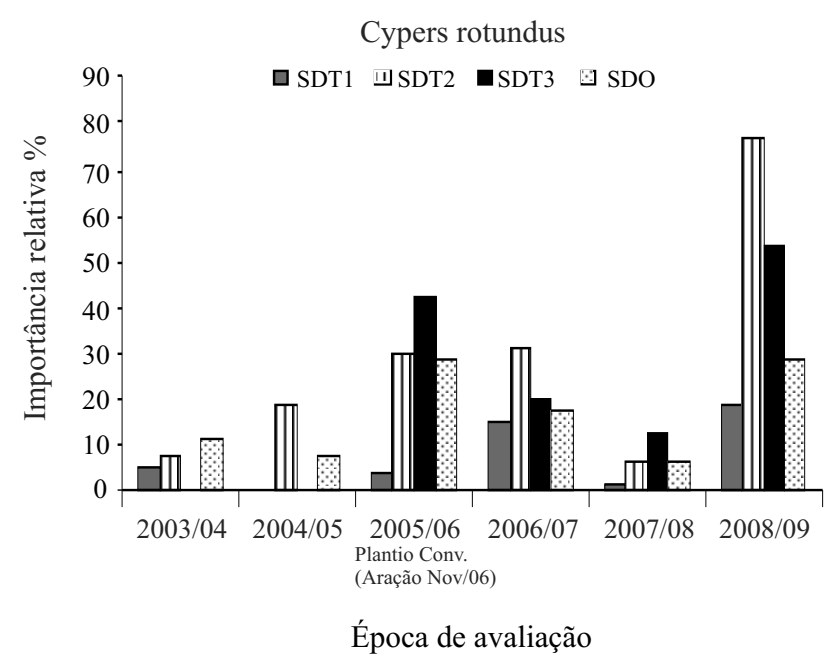

Figura 4 - Importância relativa da espécie Cyperus rotundus nos sistemas SDT1 (sem adubação com herbicida); SDT2 (com adubação mineral e com herbicida); SDT3 (adubado com composto orgânico e com herbicida) e SDO (adubado com composto orgânico e roçada), durante seis anos agrícolas

A espécie Ipomoea grandifolia apresentou IR\% baixa no sistema de plantio direto. A aração e gradagem 
estimulou a germinação da espécie, aumentando de sua IR\% em todos os sistemas estudados, com maior porcentagem no sistema de plantio direto sem adubação SDT1 (FIG. 7).

O principal meio de propagação é por sementes (GRAVENA et al., 2004), as quais apresentam dormência, sendo essa a causa dos diferentes fluxos de emergência de plantas de Ipomoea (AZANIA et al., 2009). A aração e gradagem realizada na área provavelmente contribuiu para a quebra da dormência e exposição de maior número de sementes na superfície do solo, proporcionando aumento da germinação em todos os tratamentos estudados.

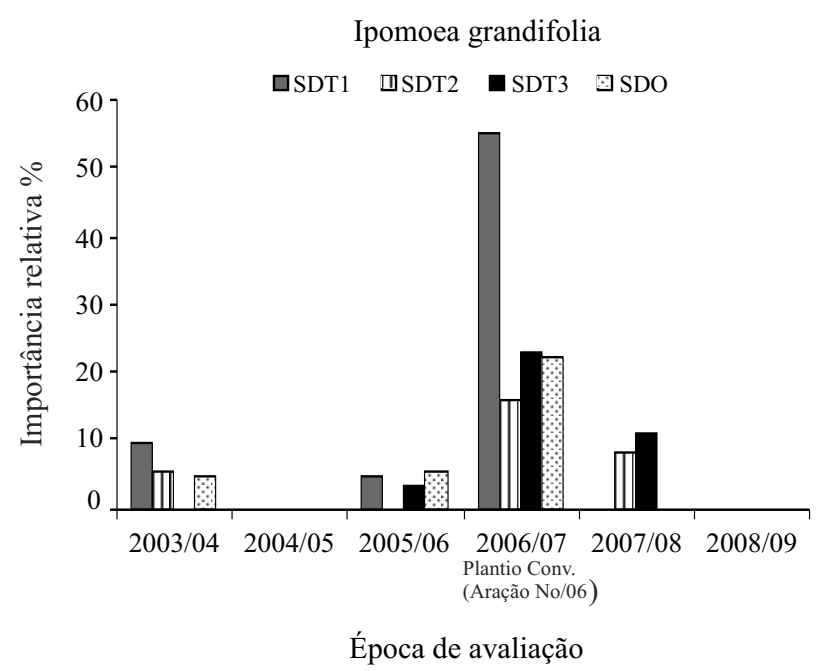

Figura 5 - Importância relativa da espécie Ipomoea grandifolia nos sistemas SDT1 (sem adubação e com herbicida); SDT2 (com adubação mineral e com herbicida); SDT3 (adubado com composto orgânico e com herbicida); e SDO (adubado com composto orgânico e roçada), durante seis anos agrícolas

A espécie Commelina benghalensis, no início de implantação do sistema plantio direto (2003/04), apresentou baixas taxas de IR\% em todos os sistemas estudados. No segundo ano, a espécie obteve elevada IR\% no SDT2 e baixa IR\% no sistema de SDO. Porém, na terceira avaliação, a espécie é observada em todos os sistemas estudados, com maior IR\% novamente para o SDT2 (FIG. 6).

Após a aração e gradagem, verificou-se controle da espécie em todos os tratamentos, mas com o retorno do plantio direto a espécie apresentou a maior importância relativa no plantio direto tradicional SDT2 e no plantio direto orgânico SDO, novamente.

A espécie $C$. bengalensis produz sementes também dentro do solo, menores e modificadas, e essas sementes têm capacidade de germinar e emergir de profundidades maiores de 10 a $15 \mathrm{~cm}$, podendo ser está uma estratégia utilizada pela espécie para germinar, mesmo em área com grande quantidade de palhada no solo.

De acordo com Pasqualetto et al. (2001), a $C$. bengalensis possui folhas com alta cerosidade, fato que dificulta seu controle quando o solo está com alta umidade, pois serve como anteparo protetor por ocasião da aplicação de herbicida dessecante como o glyphosate. Seu controle por herbicidas está relacionado com o seu grau de desenvolvimento e, em aplicações em plantas adultas, a espécie torna-se tolerante, sendo seu controle menor do que 50\% (LORENZI, 1994). Trabalhos têm verificado a tolerância da espécie $C$. bengalensis ao glyphosate, sendo esta espécie controlada apenas parcialmente pelo herbicida (CORREIA et al., 2008; MONQUERO et al., 2005).

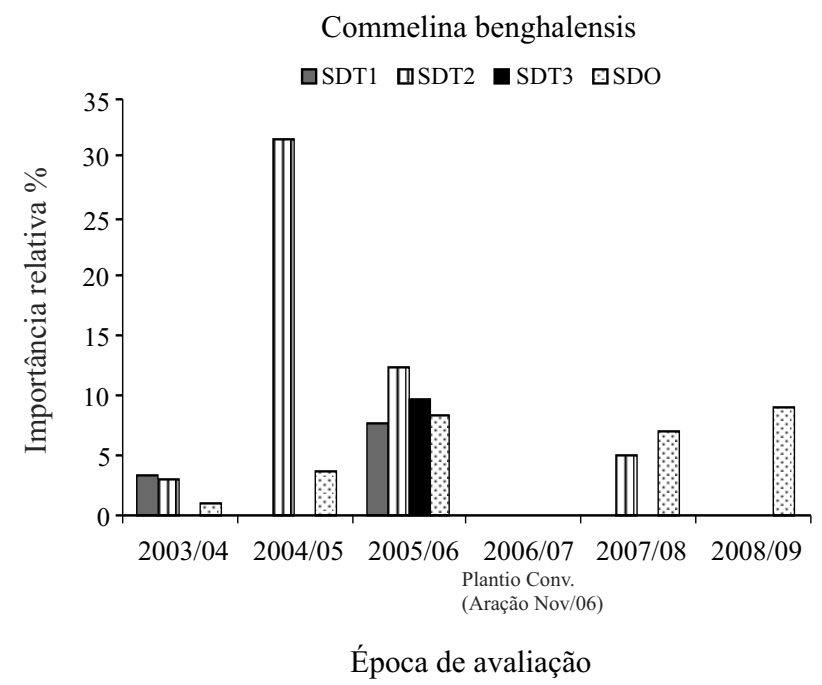

Figura 6 - Importância relativa da espécie Commelina benghalensis nos sistemas SDT1 (sem adubação e com herbicida); SDT2 (com adubação mineral e com herbicida); SDT3 (adubado com composto orgânico e com herbicida); e SDO (adubado com composto orgânico e roçada), durante seis anos agrícolas

Em ordem decrescente de importância relativa das espécies ao longo das avaliações destacam-se Artemisia verlotorum, Cyperus rotundus, Ipomoea grandifolia, Bidens pilosa, Digitaria sp., Cynodon dactylon e a Commelina benghalensis, com taxas de IR\% variando de 90 a $35 \%$, e as maiores frequências, isto é, o maior número de ocorrência, ao longo de seis safras agrícolas, ficou para as espécies Artemísia verlotorum, Cyperus rotundus e Cynodon dactylon, nos quatro sistemas estudados.

Os sistemas de plantio direto estudados estão em fase de transição e estabelecimento, sendo comuns as flutuações, na comunidade, das espécies de plantas 
daninhas que, com o passar do tempo de adoção do sistema, tendem a se estabelecer ou ainda se extinguir. De acordo com Zanin et al. (1997), a evolução florística da comunidade ocorre de acordo com a intensidade, a regularidade e o tempo de utilização do sistema de preparo do solo. Dependendo da intensidade, essas alterações podem afetar o manejo, o controle e a competição exercida por essa comunidade com a cultura (GHERSA et al., 2000 apud SILVA et al., 2005).

Dessa forma, é importante a continuidade dos estudos do efeito da aração como forma de manejo das plantas daninhas no plantio direto orgânico, após alguns anos de plantio direto. Como foi demonstrada na área em estudo, a infestação das plantas daninhas no sistema orgânico atinge em 3 ou 4 anos níveis de infestação que inviabilizam a produção de milho. Nesse caso, a aração e a gradagem a cada três ou quatro anos agrícolas facilitariam o manejo das plantas daninhas, apesar de não manter todos os benefícios do sistema de plantio direto.

\section{Conclusões}

1. A dinâmica populacional de plantas daninhas na cultura do milho foi influenciada pelo manejo do solo (aração e gradagem) e pelo manejo de plantas daninhas (herbicida ou roçada);

2. O tipo de adubação não influencia a dinâmica de plantas daninhas.

\section{Referências}

AZANIA, C. A. M. et al. Superação da dormência de sementes de corda-de-viola (Ipomoea quamoclit e I. hederifolia). Planta Daninha, v. 27 n. 01, p. 23-27, 2009.

BRIGHENTI, A. M. et al. Crescimento e partição de assimilados em losna Revista Brasileira de Fisiologia Vegetal, v. 05, n. 01, p. 41-45, 1993.

CARDINA, J.; REGNIER, E.; SPARROW, D. Velvetleaf (Abutilon theophrasti) competition and economic thresholds in conventional and no-till corn (Zea mays). Weed Science, v. 43, p. 81-87, 1995.

CARVAlHO, L. B. et al. Estudo comparativo do acúmulo de massa seca e macronutrientes por plantas de milho var. BR-106 e Brachiaria plantaginea. Planta Daninha, v. 25, n. 02, p. 293-301, 2007.

CARVALHO, L. B. et al. Interferência e estudo fitossociológico da comunidade infestante em beterraba de semeadura direta. Planta Daninha, v. 26, n. 02, p. 291-299, 2008.

CORREIA, N. M; DURIGAN, J. C.; LEITE, G. J. Seletividade da soja transgênica tolerante ao glyphosate e eficácia de controle de Commelina benghalensis com herbicidas aplicados isolados e em misturas. Revista Bragantia, v. 67, n. 03, p. 663-671, 2008.

CHIOVATO, M. G. et al. Diferentes densidades de plantas daninhas e métodos de controle nos componentes de produção do milho organico. Planta Daninha, v. 25, n. 02, p. 277-283, 2007.

CRUZ, J. C. et al. Manejo da Cultura do milho em sistema de plantio direto. Informe agropecuário, v. 27, n. 233, p. 42-53, 2006.

DIAS, A. C. R. et al. Problemática da ocorrência de diferentes espécies de capim colchão (Digitaria spp.) na cultura da canade-açúcar. Planta Daninha, v. 25, n. 02, p. 489-499, 2007.

FERREIRA, F. A. et al. Manejo de plantas daninhas em hortaliças. In: FERREIRA, Lino Roberto; SILVA, Antônio Alberto da; GOMES, Jorge Magalhães (Org.). Manejo Integrado: Doenças, Pragas e Plantas Daninhas. Viçosa: Imprensa Universitária, 2000, 2000. p. 365-372.

FONTANETTI, A. et al. Produção de milho orgânico no sistema plantio direto. Informe agropecuário, v. 27, n. 233, p. 127-136, 2006.

GALVÃO, J. C. C. Característica física e química de solo e produção de milho exclusivo e consorciado com feijão, em função de adubações orgânicas e mineral contínuas. 1995. 194 f. Tese (Doutorado em Fitotecnia) - Universidade Federal de Viçosa, Viçosa.

GRAVENA, R. et al. Controle de plantas daninhas através da palha de cana-de-açúcar associada à mistura dos herbicidas trifloxysulfuron sodium + ametrina. Planta Daninha, v. 22, n. 02, p. 419-427, 2004.

JAKELAITIS, A. et al. Manejo de plantas daninhas no consórcio de milho com capim braquiária (Brachiaria decumbens). Planta daninha, v. 22, n. 04, p. 553-560, 2004.

JAKELAITIS, A. et al. Dinâmica populacional de plantas daninhas sob diferentes sistemas de manejo nas culturas de milho e feijão. Planta Daninha, v. 21, n. 01, p. 71-79, 2003 a.

JAKELAITIS, A. et al. Efeitos de sistemas de manejo sobre a população de tiririca. Planta Daninha, v. 21, n. 01, p. 8995, 2003b.

KOZLOWSKI, L. A. et al. Período crítico de interferência das plantas daninhas na cultura do feijoeiro-comum em sistema de semeadura direta. Planta Daninha, v. 20, n. 02, p. 213-220, 2002.

LORENZI, H. Manual de identificação e controle de plantas daninhas: plantio direto e convencional. 4. ed. Nova Odessa, SP: Plantarum, 1994. 299 p.LORENZI, H. Plantas daninhas do Brasil: terrestres, aquáticas, parasitas, tóxicas e medicinais. 3. ed. Nova Odessa: Instituto plantarum, 2000. 608 p.

MILES, J. E.; NISHIMOTO, R. K.; KAWABATA, O. Diurnally alternating temperatures stimulates sprouting of purple nutsedge (Cyperus rotundus) tubers. Weed Science, v. 44, p. 122-125, 1996.

MONQUERO, P. A.; CURY, J. C.; CHRISTOFFOLETI, P. J. Controle pelo glyphosate e caracterização geral da superfície foliar de Commelina benghalensis, Ipomoea hederifolia, 
Richardia brasiliensis e Galinsoga parviflora. Planta Daninha, v. 23, n. 01, p. 123-132, 2005.

PASQUALETTO, A. et al. Ocorrência de plantas daninhas na cultura do milho (Zea mays 1.) em sucessão a culturas de safrinha no sistema plantio direto. Pesquisa Agropecuária Tropical, v. 31, n. 02, p. 133-138, 2001

PITELLI, R. A. Estudos fitossociológicos em comunidades infestantes de agroecossistemas. Journal Conserb, v. 01, n. 02, p. 01-07, 2000.

SILVA, A. A. da; JAKELAITIS, A.; FERREIRA, L. R. Milho e feijão: A tiririca é considerada a planta daninha mais disseminada e nociva do mundo; saiba como fazer o manejo adequado, prejuízo a vista. Revista cultivar, p. 12$16,2002$.

SILVA, A. A. da et al. Aspectos Fitossociológicos da comunidade de plantas daninhas na cultura do feijão sob diferentes sistemas de preparo do solo. Planta Daninha, v. 23, n. 01, p. 17-24, 2005.

SOUZA, M. C. et al. Emergência de Bidens pilosa em diferentes profundidades de semeadura. Planta Daninha, v. 27, n. 01 , p. 29-34, 2009

TRAVLOS, I. S. et al. Potential effects of diurnally alternating temperatures and solarization on purple nutsedge (Cyperus rotundus) tuber sprouting. Journal of Arid Environments, v. 73, n. 01,p. 22-25, 2009.

VAZ de MELO, A. Sistema de plantio direto para milhoverde. 2004. 61 f. Dissertação (Mestrado em Fitotecnia) Universidade Federal de Viçosa, Viçosa.

ZANIN, G. et al. Ecological interpretation of weed flora dynamics under different tillage systems. Agriculture, Ecosystems \& Environroument, v. 66, n. 03, p. 177-188, 1997. 